\title{
PERANCANGAN SIMULASI PRA UNBK BERDASARKAN JARINGAN KLIEN SERVER
}

\author{
Sapri, Liza Yulianti \\ Program Studi Informatika Fakultas Ilmu Komputer Universitas Dehasen Bengkulu \\ J1. Meranti Raya No. 32 Kota Bengkulu 38228 Telp. (0736) 22027, 26957 Fax. (0736) 341139; \\ sapriukubarulyahoo.co.id, liza.yulianti@unived.ac.id
}

\begin{abstract}
North Bengkulu 3 Vocational High School has implemented a pre-UNBK examination system using computerization which was carried out 3 times. Pre-UNBK Simulation Based on Client-Server Network was built to help students take part in the implementation of the test and introduce the examination system that already uses computerization. This simulation system is made with 2 application interface access rights namely administrators and students. Administrators can manage the data of questions, answers, and participants of the Pre UNBK simulation. While students can take the exam on the application by working on the questions that have been given. Pre UNBK simulation where this application will be stored on the server, so the client will access the application via the IP Address of the server. Based on the functions and features of the application, it has been running according to the design, and students can access the Pre UNBK simulation application simultaneously.
\end{abstract}

Keywords: Simulation, Pre UNBK, Client Server

\begin{abstract}
Abstrak - Sekolah Menengah Kejuruan Negeri 3 Bengkulu Utara sudah menerapkan sistem ujian pra UNBK menggunakan komputerisasi yang dilaksanakan 3 kali. Simulasi Pra UNBK Berbasis Jaringan Client Server dibangun untuk membantu siswa-siswa dalam mengikuti pelaksanaan ujian dan mengenalkan sistem ujian yang sudah menggunakan komputerisasi. Sistem simulasi ini dibuat dengan 2 hak akses antar muka aplikasi yaitu administrator dan siswa. Administrator dapat mengelola data soal, jawaban, serta peserta simulasi Pra UNBK. Sedangkan siswa dapat mengikuti ujian pada aplikasi dengan mengerjakan soal-soal yang telah diberikan. Simulasi Pra UNBK dimana aplikasi ini akan disimpan di server, sehingga client akan mengakses aplikasi lewat IP Address dari server tersebut. Berdasarkan fungsi dan fitur dari aplikasi sudah berjalan sesuai dengan rancangan dan siswa dapat mengakses aplikasi simulasi Pra UNBK secara serentak.
\end{abstract}

Kata Kunci : Simulasi, Pra UNBK, Client Server

\section{PENDAHULUAN}

Seiring dengan berkem-bangnya teknologi saat ini, sistem ujian manual atau sering disebut dengan konvensional secara bertahap ingin diubah menjadi sistem ujian terkomputerisasi. Penguji tidak lagi melakukan pemeriksaan satu persatu pada lembar jawaban peserta kemudian menghitung skor melainkan nilai telah tersedia oleh perangkat lunak dalam basis data dengan penghitungan otomatis berdasarkan jawaban dari peserta. Keuntungan lain yang bisa diperoleh adalah pengurangan penggunaan kertas serta pengurangan bentuk kecurangan yang dilakukan peserta. Waktu dan tempat pelaksanaan dapat diatur sedemikian rupa sehingga menyulitkan bagi peserta untuk melaksanakan tindak kecurangan.

Ujian Nasional dengan model PBT merupakan pelaksanaan ujian secara tertulis seperti yang dilakukan selama ini, sedang model CBT yang disebut Ujian Nasional Berbasis Komputer (UNBK) merupakan tolak ukur para siswa dalam mengikuti ujian berbasis komputer dengan soal yang setara dengan ujian model PBT. Dalam pelaksanaan ujian berbasis komputer terutama untuk memudahkan pelaksana dalam membuat soal beragam dengan mengombinasikan beberapa paket soal sebab dalam ujian nasional menggunakan soal yang berbeda antar peserta didik dengan tingkat kesukaran relatif setara.
Sekolah Menengah Kejuruan Negeri 3 Bengkulu Utara merupakan salah satu sekolah kejuruan Negeri yang terdapat di Bengkulu Utara yang sudah menerapkan sistem ujian pra UNBK menggunakan komputerisasi yang dilaksanakan 3 kali. Dalam pelaksanaan ujian bersifat online sehingga membutuhkan akses internet. Namun terdapat beberapa siswa/i yang masih belum memahami sistem ujian pra UNBK bersifat online, sehingga pada pelaksanaannya kebanyakan siswa tidak dapat menyelesaikan soal yang diberikan.

Dalam penelitian ini akan dibangun sistem ujian berbasis jaringan client server sebagai alternatif untuk melatih siswa-siswi agar dapat mengikuti pelaksanaan ujian berbasis komputerisasi. Perancangan sistem ujian ini bersifat offline sehingga membutuhkan Laboratorium yang sudah dilengkapi jaringan LAN, di mana terdapat Server dan Client.

Berdasarkan uraian di atas, maka peneliti tertarik untuk mengangkat studi kasus yaitu "Perancangan Simulasi Pra UNBK Berbasis Jaringan Client Server".

\section{A. Pengertian Sistem}

Sistem merupakan suatu jaringan cara kerjanya sesuai dengan prosedur-prosedur yang saling berhubungan satu sama lain, kumpulan komponen yang akan melakukan suatu kegiatan untuk menyelesaikan suatu sasaran yang tertentu, sistem kerja dalam jaringan 
yaitu terkoneksi suatu prosedur yang saling terhubungan satu dengan lain untuk menyelesaikan tujuan dan sasaran yang dimaksud[1].

Sistem juga merupakan kumpulan /group/ komponen apapun baik fisik yang saling terhubungan satu sama lain dan kerja sama secara harmonis untuk mencapai satu tujuan tertentu. Ada dua kelompok cara pendekatan di dalam mendefinisikan sistem, dengan menekankan pada prosedur untuk dapat menekankan pada komponen yang sudag ditentukan atau pada elemennya[2].

Karakteristik Sistem / Elemen Sistem[2]:

a. Memiliki komponen

b. Batas sistem (boundary)

c. Lingkungan luar sistem (environment)

d. Penghubung sistem (interface)

e. Masukan sistem (input)

f. Keluaran sistem (Output)

g. Pengolah sistem (Process)

h. Sasaran sistem

\section{B. Pengertian Jaringan Komputer}

Oetomo dalam Herlambang yang dikutip oleh Khasanah[3] "mengemukakan bahwa Jaringan komputer merupakan sekelompok komputer otonom yang saling menggunakan protokol komunikasi melalui media komunikasi sehingga dapat berbagi data, informasi, program aplikasi, dan perangkat keras seperti printer, scanner, CD-Drive ataupun harddisk, serta memungkinkan untuk dapat saling berkomunikasi secara elektronik".

\section{Pengertian Client server}

Client server "client" ini merupakan perangkat yang menerima serta menampilkan dan menjalankan sebagaimana tugas untuk melakukan sinkronsisasi dalam suatu jaringan terhadap software komputer (aplikasi). Sedangakan Server adalah sebuah sistem komputer yang menyediakan jenis layanan (service) tertentu dalam sebuah jaringan komputer dan tempat penyimpanan dan mengolah database[4].

Terdapat beberapa arsitektur client server yang digunakan untuk melakukan pemrograman database, yaitu :

\section{1-Tier\& 2-tier (Standalone)}
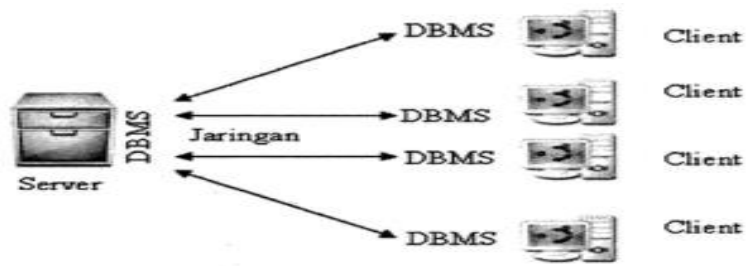

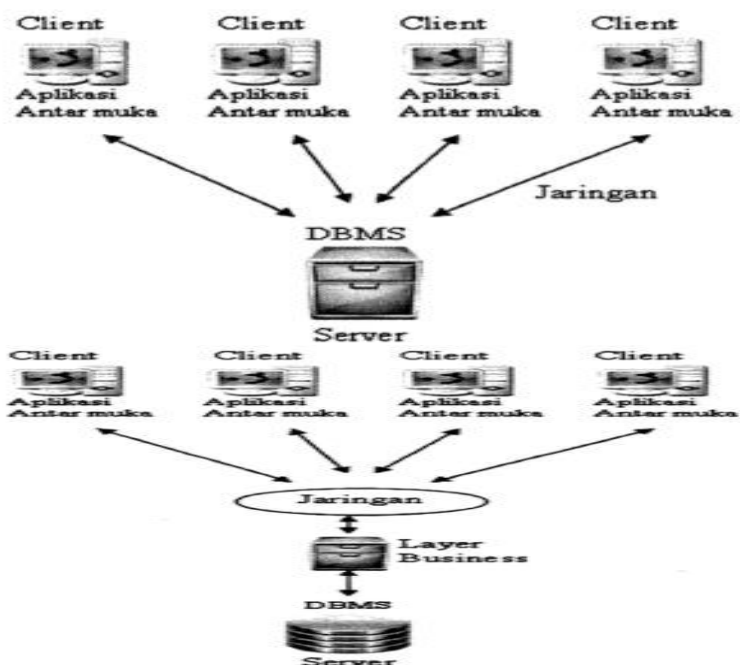

Gambar 1 Arsitektur Client Server 1-tier, 2Tier, 3-tier

\section{Back-End dan Front-End}

Halaman Back-end akan mempermudahkan seorang user untuk meng-update lainnya.

Menurut Mulyana[5], Front-end mengacu pada setiap aspek dari proses desain dan lebih berfokus pada tampilan luarnya (layout). sedangkan dari front-end merupakan desain grafis dan pembuatan gambar, desain antarmuka, desain informasi dan lain-lainnya.

\section{Adobe Dreamweaver CC 2018}

Adobe Dreamweaver yaitu Aplikasi pengembang web ini sangat digemari oleh web desainer dalam merancang web sebab perangkat lunak komputer ini memiliki kelebihan dan kemudahan dalam penggunaannya. Dengan menggunakan aplikasi ini, pengembangan web dapat dilakukan secara visual, sehingga hasil perancangan web dapat langsung terlihat tanpa harus menggunakan aplikasi bantu peramban seperti Google Chrome, Firefox atau Internet Explorer. Adobe Dreamweaver sangat beragam, salah satunya adalah teknologi untuk kebutuhan pengembangan web berbasis mobile[6].

Langkah-langkah dalam membuat aplikasi Adobe Dreamweaver CC 2018, antara lain :

1. Klik Start, dan Pilih Adobe Dreamweaver CC 2018, seperti Gambar 2.4 .

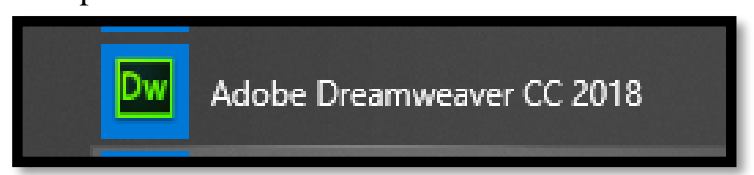

Gambar 2. Pilih Adobe Dreamweaver CC 2018

\section{E. Bahasa Pemrograman PHP}

PHP (Hypertext Preprocessor) atau disingkat dengan PHP ini adalah suatu bahasa scripting khususnya digunakan untuk web development. Pada umumnya PHP lebih banyak digunakan bersamaan dengan file bertipe HTML. Dengan menggunakan PHP dapat membuat websitepowerful yang dinamis dengan disertai manajemen database[7]. 


\section{F. Database MySQL}

Data adalah representasi fakta dunia nyata yang mewakili suatu objek seperti manusia (pegawai, siswa, pembeli, pelanggan), barang, hewan, peristiwa, konsep, keadaan dan sebagainya yang diwujudkan dalam bentuk angka[8].

Database Management Studio (DBMS) adalah aplikasi yang dipakai untuk mengelola basis data. DBMS biasanya menawarkan beberapa kemampuan yang terintegrasi seperti[7].

MySQL adalah sebuah implementasi dari sistem manajemen basis data relasional (RDBMS) yang didistribusikan secara gratis di bawah lisensi GPL (General Public License). MySQL sebenarnya merupakan turunan salah satu konsep utama dalam basis data yang telah ada sebelumnya SQL (Structured Query Language). SQL adalah sebuah konsep pengoperasian basis data, terutama untuk pemilihan atau seleksi dan pemasukan data, yang memungkinkan pengoperasian data dikerjakan dengan mudah secara otomatis[8].

\section{G. Data Flow Diagram}

Adapun pengertian secara umum dari Data Flow Diagram ini adalah suatu Networks yang menggambarkan suatu sistem automat/komputerisasi, kanalisasi, atau gabungan dari keduanya, yang penggambarannya disusun dalam bentuk kumpulan komponen sistem yang saling berhubungan sesuai dengan aturan mainnya. Keuntungan penggunaan DFD adalah memungkinkan untuk menggambarkan sistem dari level yang paling tinggi kemudian menguraikannya menjadi level yang lebih rendah (dekomposisi). Sedangkan kekurangan penggunaan DFD adalah tidak menunjukkan proses pengulangan (looping), proses keputusan, dan proses perhitungan[10].

\section{H. Entity Relationship Diagram}

ERD digunakan untuk menjelaskan hubungan antar data dalam basis data kepada pengguna secara logik. ERD didasarkan pada suatu persepsi bahwa real world terdiri atas objek-objek dasar yang mempunyai hubungan/kerelasian antar objek-objek dasar tersebut. ERD digambarkan dalam bentuk diagram yang disebut diagram ER (ER Diagram / ERD). Untuk menggambarkan ERD digunakan simbol-simbol grafis tertentu[11].

ER-D (Entity Relationship Diagram) adalah suatu pemodelan berbasis pada persepsi dunia nyata yang mana terdiri dari kumpulan objek dasar yang disebut dengan entitas (entity) dan hubungan diantara objekobjek tersebut dengan menggunakan perangkat konseptual dalam bentuk diagram. Sebuah entitas adalah objek yang dibedakan dari objek yang lain oleh himpunan dari atribut[12].

Dalam database perusahaan akan berisi berbagai informasi, namun pada pemodelan ini hanya mempertimbangkan entitas dan hubungannya. Namun demikian, mungkin tidak semua hubungan antar entitas yang terjadi dalam perusahaan dapat semuanya terekam dalam database. Yang dijabarkan pada model diagram ini hanyalah entitas yang dirasa akan masuk ke dalam desain database[13].

Tabel 1. Simbol ERD

\begin{tabular}{|c|c|c|}
\hline Simbol & $\begin{array}{c}\text { Keteran } \\
\text { gan }\end{array}$ & Penjelasan \\
\hline & Entitas & $\begin{array}{lll}\text { Suatu objek yang } & \text { dapat } \\
\text { dibedakan dengan objek } & \text { dainnya. Berfungsi } & \text { untuk } \\
\text { memberikan identitas pada } & \text { memiliki label } \\
\text { entitas yang mem } & & \\
\text { dan nama. } & & \end{array}$ \\
\hline & Relasi & $\begin{array}{l}\text { Hubungan yang terjadi antara } \\
1 \text { entitas atau lebih yang tidak } \\
\text { mempunyai fisik tetapi hanya } \\
\text { sebagai konseptual. Dan } \\
\text { berfungsi untuk mengetahui } \\
\text { jenis hubungan yang ada } \\
\text { antara } 2 \text { file. }\end{array}$ \\
\hline & $\begin{array}{c}\text { Garis } \\
\text { Hubung } \\
\text { an }\end{array}$ & $\begin{array}{lr}\text { Berfungsi } & \text { untuk } \\
\text { menghubungkan } & \text { atribut } \\
\text { dengan entitas dan entitas } \\
\text { dengan relasi. }\end{array}$ \\
\hline & Atribut & $\begin{array}{l}\text { Karakteristik dari entitas atau } \\
\text { relasi yang menyediakan } \\
\text { penjelasan detail tentang } \\
\text { entitas atau relasi tersebut. } \\
\text { Dan berfungsi untuk } \\
\text { memperjelas atribut yang } \\
\text { dimiliki oleh sebuah entitas. }\end{array}$ \\
\hline
\end{tabular}

\section{Flowchart}

Flowchart adalah digunakan untuk merepresentasikan maupun mendesain program. Oleh karena itu flowchart harus bisa merepresentasikan komponen-komponen dalam bahasa pemrograman[14].

\section{METODOLOGI PENELITIAN}

\section{Subjek Penelitian}

Pada tanggal 21 Juli 2003 berdirilah sekolah yang diberi nama Sekolah Menengah Kejuruan (SMK) di Padang Jaya. Jurusan yang dibuka pada saat itu, yaitu jurusan pertanian. Penentuan jurusan ini sesuai dengan kebutuhan masyarakat dan kondisi wilayah setempat. Tahun 2005 mendapat proyek pertama pembuatan ruang kelas, yang berlokasi di Jalan A. Yani RT. 2 RW. 3 Desa Sidomukti Kecamatan Padang Jaya Kabupaten Bengkulu Utara.

\section{Tempat dan Waktu Penelitian}

Tempat penelitian dilaksanakan di Sekolah Menengah Kejuruan Negeri 3 Bengkulu Utara yang beralamat di Jalan A. Yani RT. 2 RW. 3 Desa Sidomukti Kecamatan Padang Jaya Kabupaten Bengkulu Utara. Waktu penelitian dimulai pada Bulan Juni 2019 sampai dengan November 2019.

Struktur Organisasi

Struktur organisasi pada Sekolah Menengah Kejuruan Negeri 3 Bengkulu Utara. 


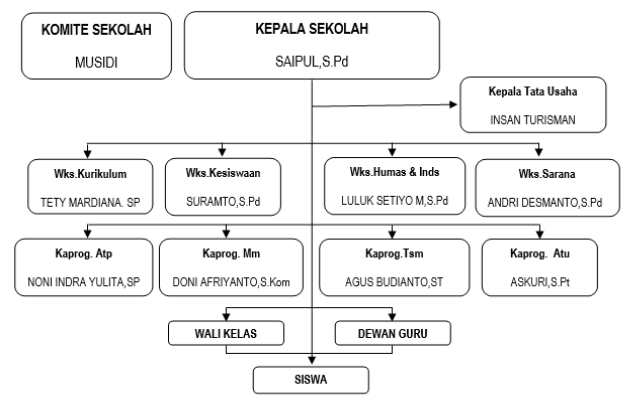

\begin{tabular}{|l|l|l|l|}
\hline$\longrightarrow=$ Garis Intruksi & \multicolumn{2}{|l|}{ Kaprog = Ketua Program Keahlian } & \multicolumn{2}{|c|}{ MM = Multi Media } \\
\hline TSM = Teknik Sepeda Motor & ATU = Agribisnis Ternak Unggas & ATP = Agribisnis Tanaman Perkebunan \\
\hline
\end{tabular}

Gambar 3. Struktur Organisasi

3. Metode Penelitian

Dalam melaksanakan penelitian ini, penulis menggunakan metode System Development Life Cycle (SDLC). SDLC ini berfungsi untuk menggambarkan tahapan-tahapan utama dan langkah-langkah dari setiap tahapan yang secara garis besar terbagi dalam 3 (tiga) kegiatan yaitu :
a. Analisis
b. Desain
c. Implementasi

1. Metode Pengumpulan Data

Metode pengumpulan data yang akan digunakan yaitu :

a. Observasi

b. Wawancara

c. Studi Pustaka

\section{Metode Perancangan Sistem}

Permasalahan yang sering terjadi adalah terdapat beberapa siswa/i yang masih belum memahami sistem ujian tryout bersifat online, sehingga pada pelaksanaannya kebanyakan siswa tidak dapat menyelesaikan soal yang diberikan. Selain itu juga pihak sekolah belum memiliki suatu wadah atau media aplikasi yang dapat digunakan sebagai pengenalan atau sosialisasi untuk siswa/i dalam mengikuti sistem ujian yang berbasis komputerisasi. Laboratorium yang sudah dilengkapi jaringan LAN, di mana terdapat Server dan Client.

Adapun skema sistem ujian yang ditawarkan

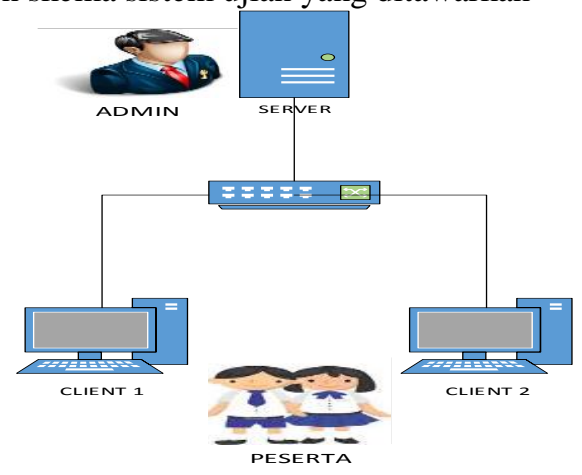

Gambar 4. Skema Sistem Ujian Yang Ditawarkan

\section{A. Data Flow Diagram}

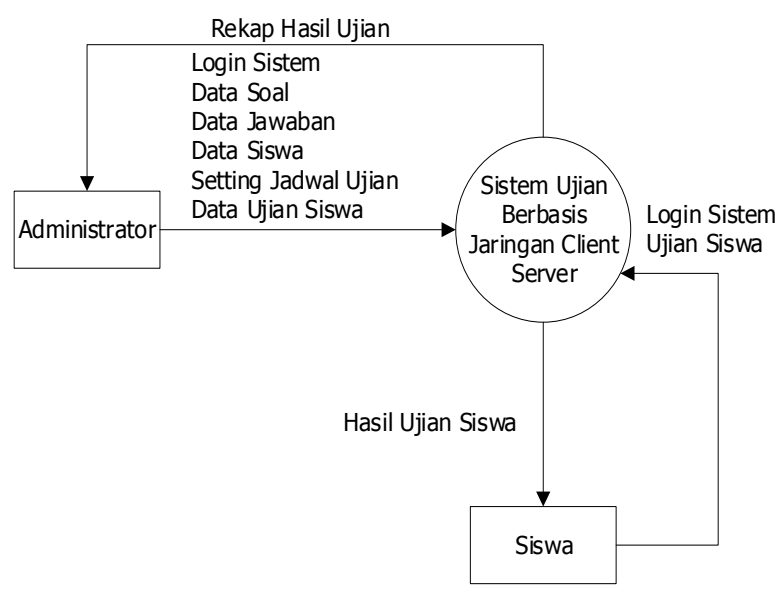

Gambar 5. Diagram Konteks

\section{B. Entity Relationship Diagram}

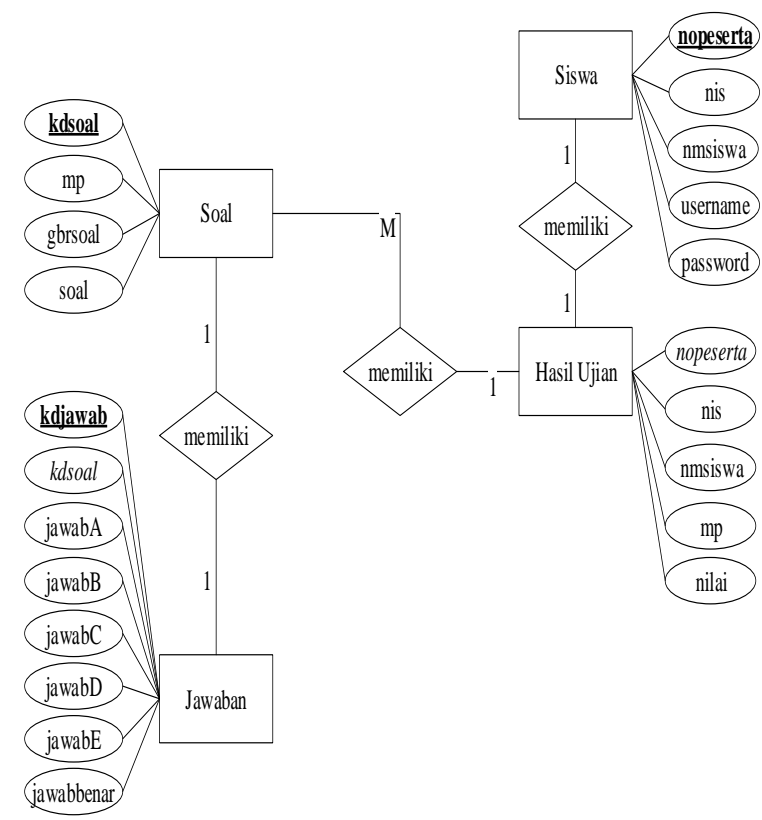

Gambar 6. Entity Relationship Diagram (ERD)

C. Struktur Menu

1. Struktur Menu Administrator 


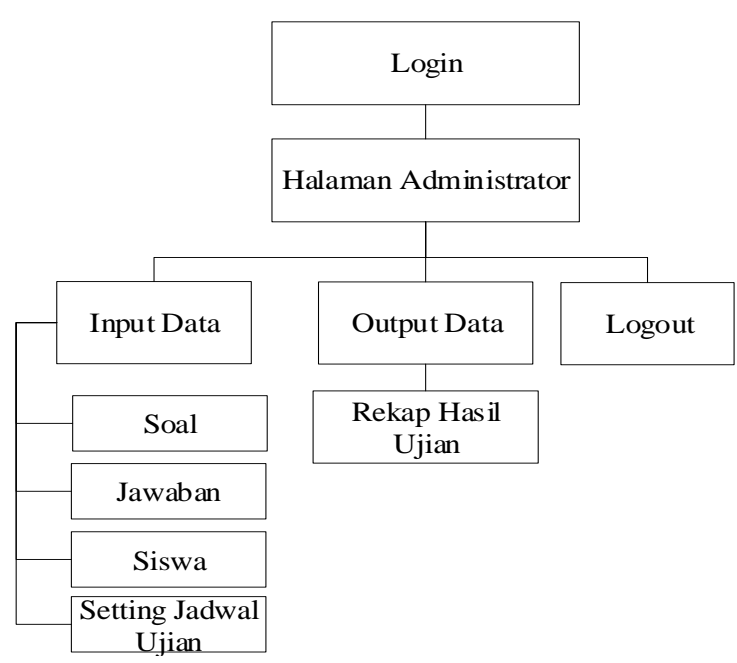

Gambar 7. Rancangan Struktur Menu Administrator

\section{Struktur Menu Siswa}

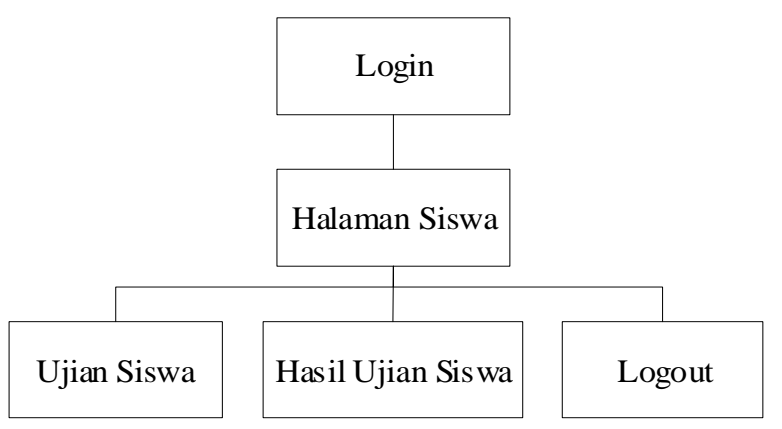

Gambar 8. Rancangan Struktur Menu Siswa

\section{Pengujian Sistem}

Pengujian ini adalah untuk menjamin bahwa perangkat lunak yang di bangun memiliki kualitas yang handal, yaitu mampu mempresentasikan kajian pokok dari spesifikasi analisis, perancangan dan pengkodean dari perangkat lunak itu sendiri.

Metode pengujian yang dipakai dalam sistem ini metode blackbox. Pengujian dilakukan dengan memberi masukan pada form aplikasi dengan data yang sah (sesuai dengan peruntukannya), dan data yang tidak sah (data yang berfungsi untuk mengeksploitasi sistem). Setelah itu tanggapan yang diberikan oleh sistem akan dicatat. Komponen pengujian sistem yang digunakan.

Tabel 2. Komponen Pengujian

\begin{tabular}{|l|l|l|l|l|}
\hline No. & \multicolumn{1}{|c|}{$\begin{array}{c}\text { Form Yang } \\
\text { Diuji }\end{array}$} & $\begin{array}{c}\text { Skenari } \\
\text { o } \\
\text { Penguji } \\
\text { an }\end{array}$ & $\begin{array}{c}\text { Hasil } \\
\text { Pengu } \\
\text { jian }\end{array}$ & $\begin{array}{c}\text { Kesim } \\
\text { pulan }\end{array}$ \\
\hline 1 & $\begin{array}{l}\text { Halaman } \\
\text { Login }\end{array}$ & & & \\
\hline 2 & $\begin{array}{l}\text { Halaman Input } \\
\text { Data Soal }\end{array}$ & & & \\
\hline 3 & $\begin{array}{l}\text { Halaman Input } \\
\text { Data } \\
\text { Pertanyaan }\end{array}$ & & & \\
\hline
\end{tabular}

\begin{tabular}{|l|l|c|c|c|}
\hline No. & $\begin{array}{c}\text { Form Yang } \\
\text { Diuji }\end{array}$ & $\begin{array}{c}\text { Skenari } \\
\text { o } \\
\text { Penguji } \\
\text { an }\end{array}$ & $\begin{array}{c}\text { Hasil } \\
\text { Pengu } \\
\text { jian }\end{array}$ & $\begin{array}{c}\text { Kesim } \\
\text { pulan }\end{array}$ \\
\hline 4 & $\begin{array}{l}\text { Halaman } \\
\text { Ujian Siswa }\end{array}$ & & & \\
\hline
\end{tabular}

\section{HASIL DAN PEMBAHASAN}

1. Hasil

Adapun hasil dari pembuatan aplikasi Simulasi Pra UNBK Berbasis Jaringan Client Server, antara lain :

a. Administrator

Untuk mengakses halaman administrator, pada link tersebut tambahkan simbol slash kemudian isi administrator, maka secara otomatis akan menampilkan halaman login.

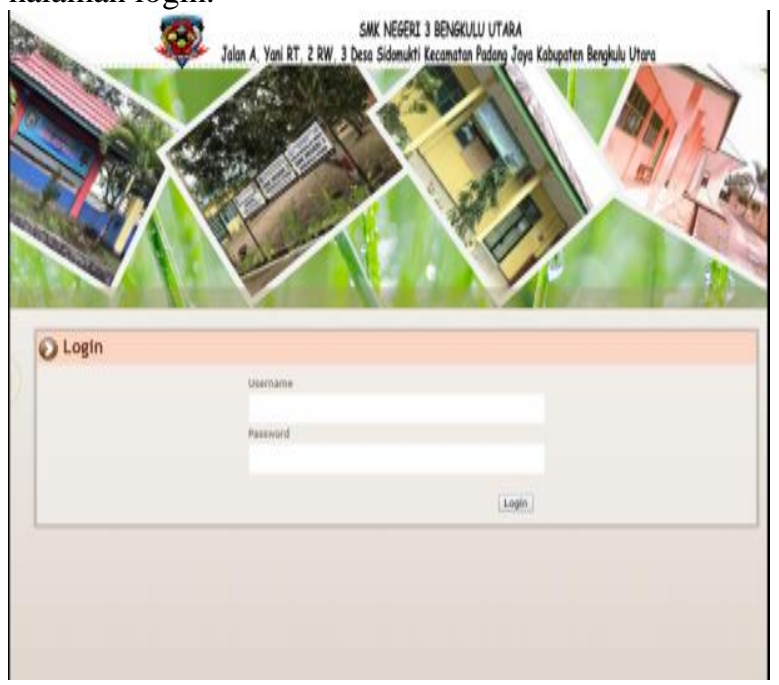

Gambar 9. Halaman Login

Admin akan memasukkan username dan password yang benar agar dapat mengakses halaman administrator. Adapun halaman administrator..

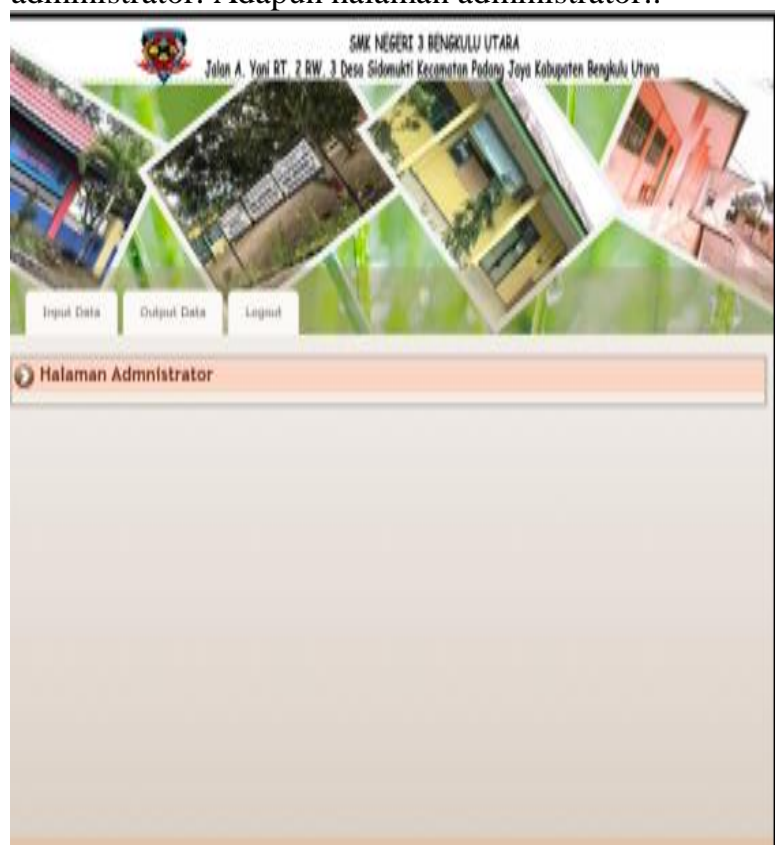

Gambar 10. Halaman Administrator 
Terdapat sub menu yang dapat diakses untuk proses pengolahan data maupun untuk mencetak laporan. Adapun form-form tersebut antara lain :

a. Halaman Input Data Soal

Admin dapat melakukan pengolahan data soal dengan cara menambah, mengoreksi serta menghapus data soal pada masing-masing mata pelajaran yang akan diujikan kesiswa. Adapun halaman input data soal seperti Gambar 4.3.

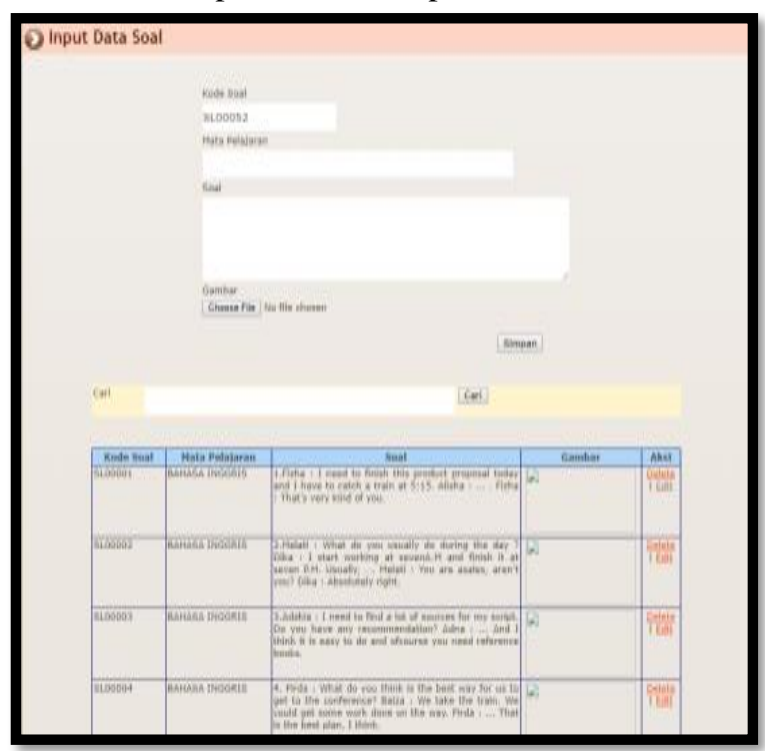

Gambar 11. Halaman Input Data Soal

\section{b. Halaman Input Data Jawaban}

Dalam penginputan data jawaban, akan diinputkan juga jawaban yang benar, untuk nantinya akan memberikan nilai secara otomatis kesiswa setelah menjawab pertanyaan. Adapun halaman input data jawaban.

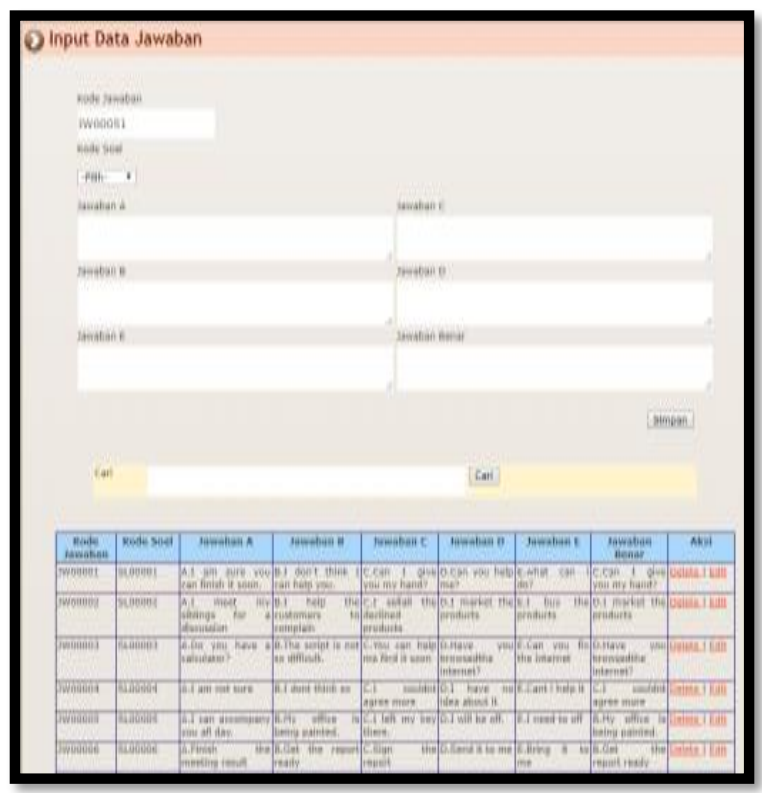

Gambar 12. Halaman Input Data Jawaban c. Halaman Input Data Siswa

Siswa akan diberikan username dan password yang dapat digunakan untuk mengakses halaman login siswa. Adapun halaman input data siswa.

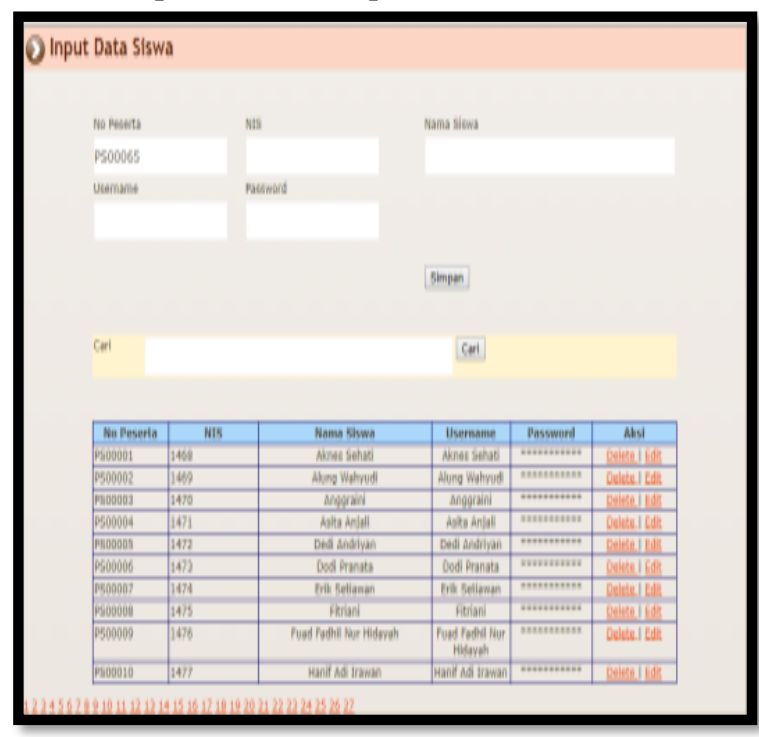

Gambar 13. Halaman Input Data Siswa

d. Halaman Input Setting Jadwal Ujian

Admin dapat melakukan setting jadwal ujian berdasarkan mata pelajaran yang akan diujikan. Setting jadwal ujian ini diperlukan agar siswa dapat mengetahui informasikan penjadwal ujian di mulai. Jika siswa login sebelum jadwal ujian dimulai maka sistem menolakan keikut serta tersebut. Adapun halaman input data setting jadwal ujian.

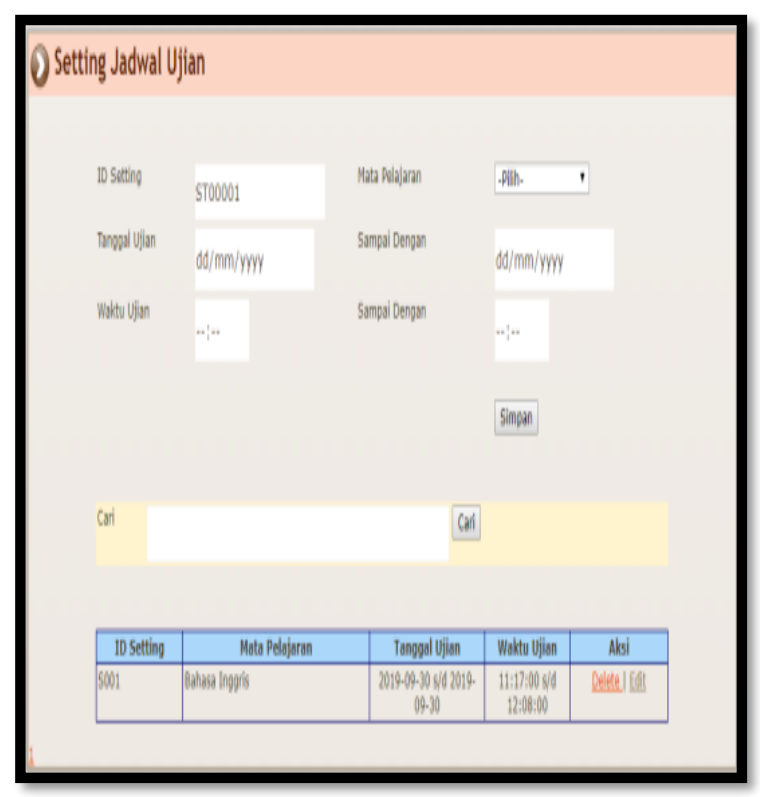

Gambar 14. Halaman Input Setting Jadwal Ujian

e. Output Rekap Hasil Ujian

Admin dapat melihat atau pun mencetak rekap hasil ujian siswa yang telah dilakukan berdasarkan 
tahun ujian dan mata pelajaran. Adapun output rekap hasil ujian..

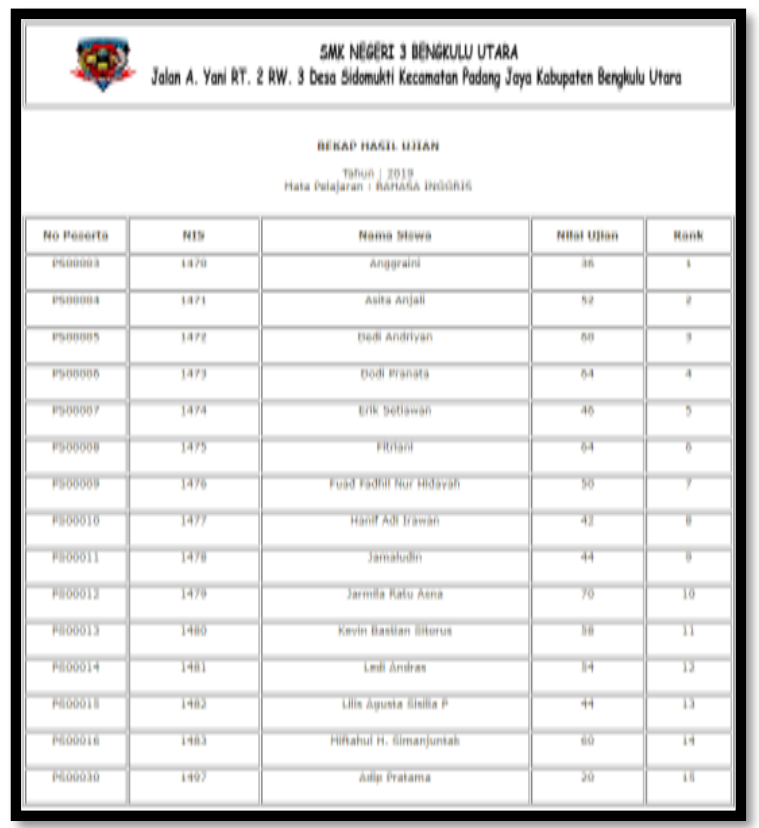

Gambar 15 Output Rekap Hasil Ujian

\section{d. Siswa}

Untuk mengakses halaman siswa, masing-masing siswa harus login terlebih dahulu keaplikasi melalui halaman login.

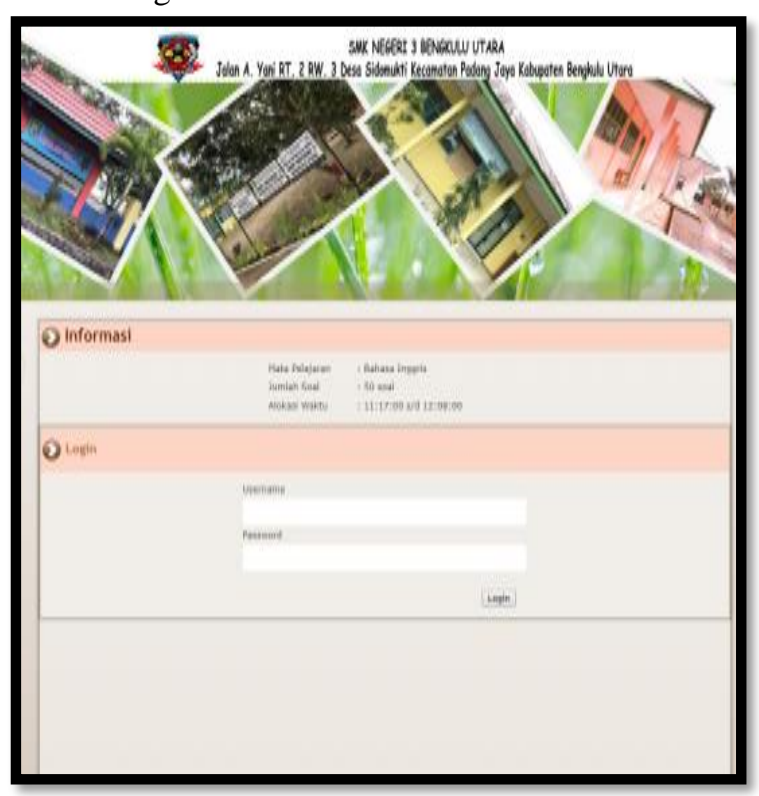

Gambar 16. Halaman Login

Terdapat informasi mata pelajaran yang diujikan, jumlah soal serta alokasi waktu ujian. Selain itu siswa harus memasukkan username dan password yang benar agar dapat masuk kehalaman siswa. Adapun halaman siswa.

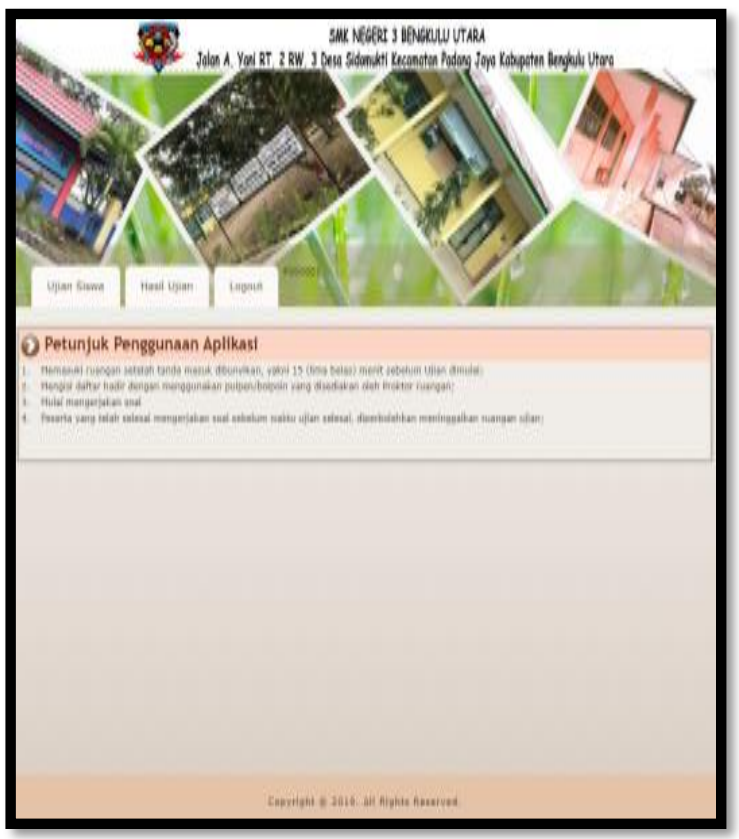

Gambar 17. Halaman Siswa

Terdapat informasi petunjuk penggunaan dari aplikasi, dan beberapa menu yang dapat diakses antara lain :

a. Ujian Siswa

Siswa dapat mengikuti ujian siswa dengan menjawab pertanyaan pada masing-masing soal yang akan tampil. Adapun halaman ujian siswa..

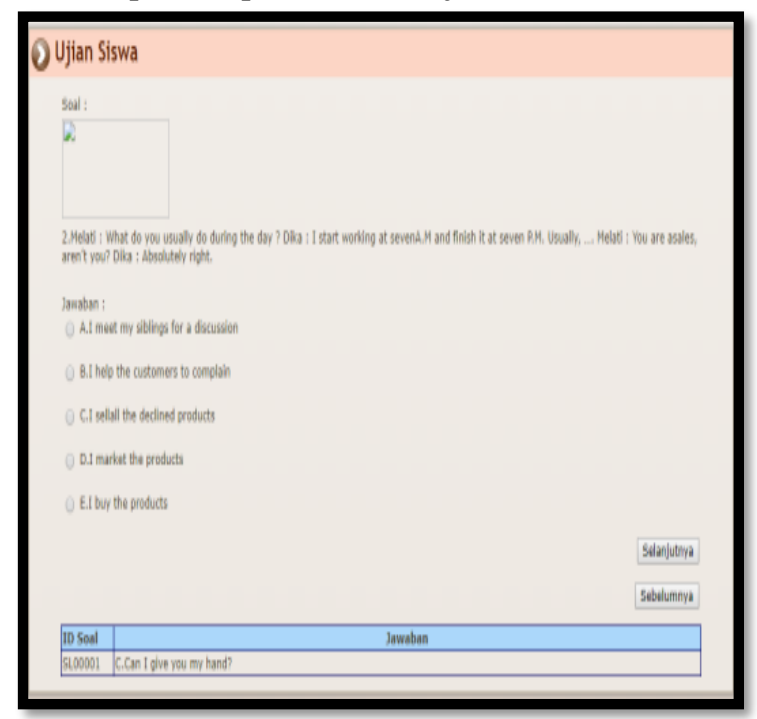

Gambar 18. HalamanUjian Siswa

b. Hasil Ujian

Siswa dapat mengetahui hasil ujian yang diperoleh berdasarkan hasil ujian yang telah dilakukan. Adapun hasil ujian. 


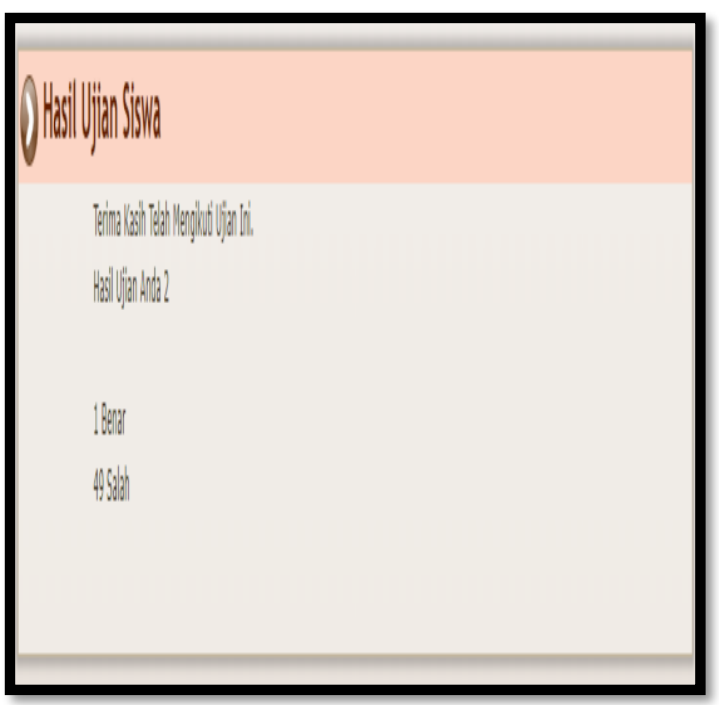

Gambar 19. Halaman Hasil Ujian

\section{Pembahasan}

Simulasi Pra UNBK Berbasis Jaringan Client Server dibangun untuk membantu siswa-siswa dalam mengikuti pelaksanaan ujian dan mengenalkan sistem ujian yang sudah menggunakan komputerisasi. Sistem simulasi ini dibuat dengan 2 hak akses antarmuka aplikasi yaitu administrator dan siswa. Administrator dapat mengelola data soal, jawaban, serta peserta simulasi Pra UNBK. Sedangkan siswa dapat mengikuti ujian pada aplikasi dengan mengerjakan soal-soal yang telah diberikan.

Simulasi Pra UNBK dibuat menggunakan bahasa pemrograman PHP dan database MySQL, dimana aplikasi ini akan disimpan di server, sehingga client akan mengakses aplikasi lewat IP Address dari server tersebut. Adapun skema Jaringan yang telah dibangun..

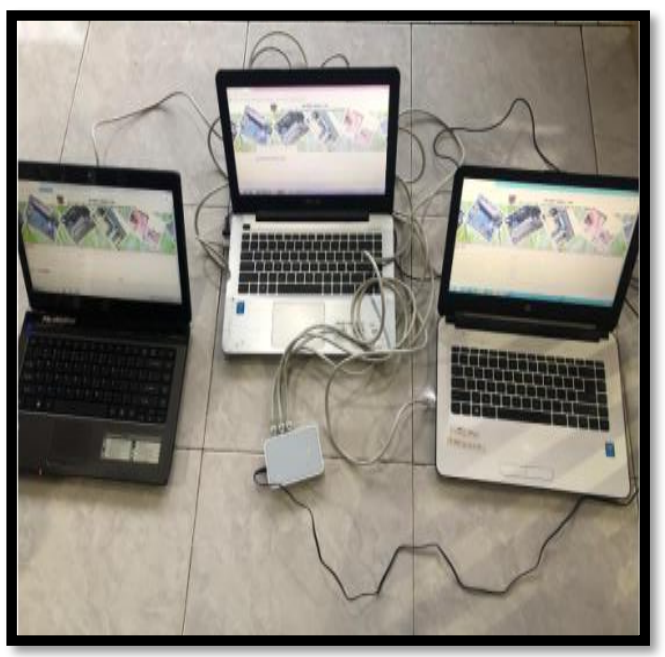

Gambar 20. Jaringan Yang TelahDibangun

Terdapat 3 laptop yang sudah terhubung dalam 1 jaringan melalui Hub. Aplikasi beserta database akan disimpan kedalam server dengan IP Address 192.168.1.1. Client dapat mengakses aplikasi dengan memasukkan link pada browser web yaitu “192.168.1.1/wilyan”. e. Hasil Pengujian Sistem

Pengujian sistem dilakukan dengan menggunakan metode blackbox, yaitu dengan menguji form data yang terdapat pada Simulasi Pra UNBK Berbasis Jaringan Client Server. Pengujian yang dilakukan antara lain :

Tabel 3 Hasil Pengujian Sistem

\begin{tabular}{|c|c|c|c|}
\hline Form & Sampel Data & $\begin{array}{l}\text { Harapan Hasil } \\
\text { Pengujian }\end{array}$ & $\begin{array}{l}\text { Hasil } \\
\text { Pengujian }\end{array}$ \\
\hline \multirow[t]{2}{*}{$\begin{array}{l}\text { Halam } \\
\text { an } \\
\text { Login }\end{array}$} & $\begin{array}{l}\text { Pengujian } \\
\text { dengan } \\
\text { memasukkan } \\
\text { username dan } \\
\text { password yang } \\
\text { salah }\end{array}$ & $\begin{array}{l}\text { Sistem menolak } \\
\text { akses tersebut } \\
\text { dengan } \\
\text { menampilkan } \\
\text { pesan kesalahan }\end{array}$ & $\begin{array}{l}\text { Admin/Siswat } \\
\text { idak dapat } \\
\text { login }\end{array}$ \\
\hline & $\begin{array}{l}\text { Pengujian } \\
\text { dengan } \\
\text { memasukkan } \\
\text { username dan } \\
\text { password yang } \\
\text { benar }\end{array}$ & $\begin{array}{l}\text { Sistem } \\
\text { menerima akses } \\
\text { tersebut dengan } \\
\text { menampilkan } \\
\text { pesan berhasil }\end{array}$ & $\begin{array}{l}\text { Admin/Siswa } \\
\text { berhasil } \\
\text { melakukan } \\
\text { login }\end{array}$ \\
\hline $\begin{array}{l}\text { Halam } \\
\text { an } \\
\text { input } \\
\text { data } \\
\text { soal }\end{array}$ & $\begin{array}{l}\text { Pengujian } \\
\text { dengan } \\
\text { menginputkan } \\
\text { data soal pada } \\
\text { halaman input } \\
\text { data soal }\end{array}$ & $\begin{array}{l}\text { Sistem berhasil } \\
\text { memproses } \\
\text { pengolahan data } \\
\text { soal sesuai yang } \\
\text { diinputkan } \\
\text { admin }\end{array}$ & $\begin{array}{l}\text { Admin dapat } \\
\text { melakukan } \\
\text { proses } \\
\text { pengolahan } \\
\text { data }\end{array}$ \\
\hline $\begin{array}{l}\text { Halam } \\
\text { an } \\
\text { input } \\
\text { data } \\
\text { jawaba } \\
\text { n }\end{array}$ & $\begin{array}{l}\text { Pengujian } \\
\text { dengan } \\
\text { menginputkan } \\
\text { data jawaban } \\
\text { pada halaman } \\
\text { input data } \\
\text { jawaban }\end{array}$ & $\begin{array}{l}\text { Sistem berhasil } \\
\text { memproses } \\
\text { pengolahan data } \\
\text { jawaban sesuai } \\
\text { yang diinputkan } \\
\text { admin }\end{array}$ & $\begin{array}{l}\text { Admin dapat } \\
\text { melakukan } \\
\text { proses } \\
\text { pengolahan } \\
\text { data }\end{array}$ \\
\hline $\begin{array}{l}\text { Halam } \\
\text { an } \\
\text { input } \\
\text { data } \\
\text { siswa }\end{array}$ & $\begin{array}{l}\text { Pengujian } \\
\text { dengan } \\
\text { menginputkan } \\
\text { data siswa pada } \\
\text { halaman input } \\
\text { data siswa }\end{array}$ & $\begin{array}{l}\text { Sistem berhasil } \\
\text { memprosespeng } \\
\text { olahan data } \\
\text { siswa sesuai } \\
\text { yang diinputkan } \\
\text { admin }\end{array}$ & $\begin{array}{l}\text { Admin dapat } \\
\text { melakukan } \\
\text { proses } \\
\text { pengolahan } \\
\text { data }\end{array}$ \\
\hline $\begin{array}{l}\text { Halam } \\
\text { an } \\
\text { input } \\
\text { data } \\
\text { setting } \\
\text { jadwal } \\
\text { ujian }\end{array}$ & \begin{tabular}{lr}
\multicolumn{2}{l}{ Pengujian } \\
dengan \\
menginputkan \\
data $r$ setting \\
jadwal & ujian \\
pada & halaman \\
input & data \\
setting & jadwal \\
ujian &
\end{tabular} & $\begin{array}{l}\text { Sistem berhasil } \\
\text { memproses } \\
\text { pengolahan data } \\
\text { setting jadwal } \\
\text { ujian sesuai } \\
\text { yang diinputkan } \\
\text { admin }\end{array}$ & $\begin{array}{l}\text { Admin dapat } \\
\text { melakukan } \\
\text { proses } \\
\text { pengolahan } \\
\text { data }\end{array}$ \\
\hline $\begin{array}{l}\text { Halam } \\
\text { an } \\
\text { Output } \\
\text { Rekap } \\
\text { Hasil } \\
\text { Ujian }\end{array}$ & $\begin{array}{l}\text { Pengujian } \\
\text { dengan } \\
\text { menampilkan } \\
\text { output } \\
\text { berdasarkan } \\
\text { tahun ujian dan } \\
\text { mata pelajaran } \\
\text { yang diuji }\end{array}$ & $\begin{array}{l}\text { Sistem berhasil } \\
\text { menampilkan } \\
\text { output } \\
\text { berdasarkan } \\
\text { tahun ujian dan } \\
\text { mata pelajaran } \\
\text { yang diuji }\end{array}$ & $\begin{array}{l}\text { Admin dapat } \\
\text { melihat } \\
\text { output rekap } \\
\text { hasil ujian. }\end{array}$ \\
\hline $\begin{array}{l}\text { Halam } \\
\text { anujian } \\
\text { siswa }\end{array}$ & $\begin{array}{l}\text { Masing-masing } \\
\text { siswa mengikuti } \\
\text { ujian secara } \\
\text { serentak }\end{array}$ & $\begin{array}{l}\text { Sistem berhasil } \\
\text { menghandel } \\
\text { ujian serentak }\end{array}$ & $\begin{array}{l}\text { Siswa } \\
\text { berhasil } \\
\text { mengikuti } \\
\text { ujian yang } \\
\text { sedang } \\
\text { berlangsung }\end{array}$ \\
\hline $\begin{array}{l}\text { Halam } \\
\text { an hasil } \\
\text { ujiansis } \\
\text { wa }\end{array}$ & $\begin{array}{l}\text { Menampilkan } \\
\text { hasil ujian } \\
\text { masing-masing } \\
\text { siswa }\end{array}$ & $\begin{array}{l}\text { Sistem berhasil } \\
\text { menampilkan } \\
\text { hasil ujian siswa }\end{array}$ & $\begin{array}{lr}\text { Siswa } & \text { dapat } \\
\text { melihat } & \text { hasil } \\
\text { ujian yang } \\
\text { telah } & \\
\text { dilakukan }\end{array}$ \\
\hline
\end{tabular}

Berdasarkan pengujian yang telah dilakukan tersebut, dapat disimpulkan bahwa : 
1. Fungsi dan fitur dari aplikasi sudah berjalan sesuai dengan rancangan.

2. Siswa dapat mengakses aplikasi simulasi pra UNBK secara serentak.

Selain itu pengujian dilakukan dengan cara memberikan kuisioner kepada responden pada saat melakukan demo program Simulasi Pra UNBK Berbasis Jaringan Client Server (data terlampir).

\section{KESIMPULAN}

Berdasarkan hasil dan pembahasan serta pengujian, maka dapat disimpulkan bahwa :

1. Simulasi Pra UNBK Berbasis Jaringan Client Server dibangun untuk membantu siswa-siswa dalam mengikuti pelaksanaan ujian dan mengenalkan sistem ujian yang sudah menggunakan komputerisasi.

2. Sistem simulasi ini dibuat dengan 2 hak akses antar muka aplikasi yaitu administrator dan siswa. Administrator dapat mengelola data soal, jawaban, serta peserta simulasi Pra UNBK. Sedangkan siswa dapat mengikuti ujian pada aplikasi dengan mengerjakan soal-soal yang telah diberikan.

3. Simulasi Pra UNBK dibuat menggunakan bahasa pemrograman PHP dan database MySQL, dimana aplikasi ini akan disimpan di server, sehingga client akan mengakses aplikasilewat IP Address dari server tersebut.

4. Pengujian yang telah dilakukan tersebut, dapat disimpulkan bahwa fungsi dan fitur dari aplikasi sudah berjalan sesuai dengan rancangan dan siswa dapat mengakses aplikasi simulasipra UNBK secara serentak.

\section{DAFTAR PUSTAKA}

[1] H. Antonio. et.all. Rancang Bangun Sistem Informasi Administrasi Informatika (SI-ADIF). Jurnal ELKHA Vol.4 No.2 2012.

[2] Istiningsih. Pengertian Sistem dan Analis Sistem. Universitas Gunadarma. 2009.

[3] F. N. Khasanah. Makalah Program Studi Teknik Informatika Universitas Muhammadiyah Surakarta. 2014.

[4] Wahana, Komputer. Penerbit Andi : Yogyakarta. 2010.

[5] A. Mulyana, M. Aria. Perancangan Digital Signage Sebagai Papan Informasi Digital. Makalah Ilmiah UNIKOM Vol.13. No.2. 2014.

[6] R. Mandar. Solusi Tepat Menjadi Pakar Adobe Dreamweaver CS6. PT. Elexmedia Komputindo : Jakarta. 2017.

[7] P. Hidayatullah. J. K. Kawistara. Pemrograman Web EdisiRevisi. Penerbit Informatika : Bandung. 2017.

[8] Fathansyah. Basis Data Edisi Revisi. Penerbit Informatika : Bandung. 2012.

[9] H. Februariyanti. E. Zuliarso. Rancang Bangun Sistem Perpustakaan Untuk Jurnal Elektronik.
Jurnal Teknologi Informasi DINAMIK Vol.17 No.2 Juli 2012. ISSN : 0954-9524. 2012.

[10] T. Sutabri. Analisis Sistem Informasi. Penerbit Andi : Yogyakarta. 2012.

[11] E. Sutanta. Basis Data DalamTinjauanKonseptual. PenerbitAndi : Yogyakarta. 2011.

[12] A. Lubis. Basis Data Dasar Untuk Mahasiswa Ilmu Komputer. Penerbit Deepublish : Yogyakarta. 2016.

[13] Mujilan, Agustinus. Universitas Widya Mandala 2013.

[14] Adelia, J. Setiawan. Jurnal Sistem Informasi Vol.6 No.2 September 2011:113-126. Fakultas Teknologi Informasi Universitas Kristen Maranatha. 2011. 